\title{
Flame Retardant Hybrid Paper Coatings with PVA - Melamine / Zinc Borat
}

\section{ABSTRACT}

Papers are raw materials with high flammability. Some of the prod-

Emine Arman Kandirmaz ucts produced in the printing industry are used in places requiring high heat resistance. High-tech papers can be produced by adding a flame retardant to the paper coating formulation or pulp. In this study, it is aimed to prepare polyvinyl alcohol (PVA )- zinc borate / melamine / zinc borate-melamine paper coating formulations and to produce flame retardant paper by coating on paper. For this purpose, primarily zinc borate is produced by boric acid and zinc carbonate reaction. In the second part of the study, four different coating formulations were prepared by adding zinc borate, melamine and their double mixtures to the main formulation, where PVA polymer matrix was used as binder, and coatings were made on an $80 \mathrm{~g} / \mathrm{m}^{2}$ paper surface. Limiting oxygen index ( $\mathrm{LOI}$ ), gloss, color, surface energy and contact angles properties of the produced papers were determined. Offset printing was done onto coated papers with IGT C1 test printing machine. All produced flame retardant papers have good printability characteristics.

\author{
Marmara University, \\ School of Applied Sciences, \\ Department of Printing Technologies, \\ Istanbul, Turkey
}

Corresponding author: Emine Arman Kandirmaz e-mail: earman@marmara.edu.tr

First recieved: 06.04.2020. Accepted: 29.04.2020.

\section{KEY WORDS}

Flame retardant, coating, printability, zinc borate, melamine

\section{Introduction}

Synthetic polymers made of petroleum are used in the packaging industry for sealing, transparency, barrier, moisture protection etc. Although they have very superior abilities, the interest of biodegradable polymers is increasing day by day due to the fact that they do not dissolve in nature for a long time and are harmful to the environment and human body (Mohanty et al, 2005; Avella et al, 2009; Auras et al, 2011; Kuorwel et al, 2011; Pilla, 2011). Biodegradable polymers can be grouped under 3 main headings. These;

1. polysaccharides (starch and cellulose), proteins (gelatin and casein), and lipids that are derived directly from natural raw materials and renewable resources;

2. poly(lactic acid) (PLA), polyvinyl alcohol (PVA) that are chemically synthesized from bio-derived monomers;
3. poly(hydroxybutyrate) (PHB), poly(hydroxyvalerate), and poly(hydroxyalkanoates) that are made from microbiologically produced materials or genetically modified bacteria (Chandra \& Rustgi, 1998; Avérous, 2008).

Natural polymers materials are being used in ever more areas and under ever more demanding environmental conditions. These include antimicrobial coatings and packaging, indicator labels and films, flame retardant coating and films, edible prints and conductive inks (Lu \& Hamerton, 2002; Duncan, 2011). Flame retardant coating and films prevent or delay the ignition of valuable documents (check, money, valuable book) or printed papers (wallpapers, laminate parks, etc.) used in a home environment, thus providing features such as providing extinguishing time or preventing the spread of fire. Such materials fall into the field of advanced polymeric applications (Siracusa et al, 2008). The use of flame 
retardants to reduce the combustibility of polymers, and smoke or toxic fume production becomes an important part of the development and application of new materials. Although halogen atoms (e.g. bromine or chlorine) form some of the most widely applied flame retardant materials, in particular for polymers used in composite organic matrices or in electronic equipment, they have obvious disadvantages: not least the potential to corrode metal components and, more pressingly, the toxicity of the hydrogen halide formed during combustion (Ren et al, 2007). For this reason, halogen-free flame retardants for polymeric materials have attracted more and more attention from scientists and engineers in recent times (Chang et al, 2004). Sometimes, some metals (zinc, aluminum, molybdenum, silicon) can be added to the polymers (Hirschler, 1984), and sometimes the polymer hybrids formed with organic compounds give the coating a fire retardant feature. Although the flame retardancy properties of zinc borate compounds cannot be fully explained, it is thought that they prevent oxygen transmission by slowing the combustion with the high ash they form (Garba, 1999). In addition, since harmful gas emission is low, it has been the subject of many studies. Nitrogen based material's main advantages are low toxicity, solid state, and in the event of fire, absence of toxic gases and low evolution of smoke (Horacek \& Grabner, 1996). The most important organic nitrogen compounds used as flame retardant additives are melamine and its derivatives. In the light of this information, in this study, coating formulations in which zinc borate, melamine and both are added together are prepared and coated on paper. Both the printability and flame retardancy properties of the coated papers were examined.

\section{Material and method}

\section{Material}

Zinc carbonate, boric acid, melamine, poly vinyl alcohol was obtained from Sigma Aldrich.

\section{Method}

\section{The Synthesis of Zinc Borate}

The synthesis of Zinc borate was carried out as indicated in the relevant literature (Acarali et al, 2015) 1.25 $\mathrm{g}$ of zinc carbonate were dissolved in $100 \mathrm{ml}$ water and $2.5 \mathrm{~g}$ boric acid refluxed in an inert atmosphere at about $95^{\circ} \mathrm{C}$ for 2 hours stirred $500 \mathrm{rpm}$. The resulting suspension was rapidly filtered at the same temperature and dried in a vacuum oven at room temperature. Percentage of yield was calculated as $88 \%$.

\section{Preparation of formulations and coating on paper}

In this part of the study, coating formulations are prepared according to Table 1 . The paper sample described as FO is $80 \mathrm{~g} / \mathrm{m}^{2}$ office paper that has never been processed. Used for the purpose of the control group.

Table 1

Formulation of paper coatings

\begin{tabular}{c|c|c|c|c}
\hline Formulation & $\begin{array}{c}\text { Poly Vinyl } \\
\text { Alcohol } \\
\text { (PVA) \% }\end{array}$ & Water \% & $\begin{array}{c}\text { Zinc } \\
\text { Borate \% }\end{array}$ & Melamine \% \\
\hline F0 & 0 & 0 & 0 & 0 \\
\hline F1 & 20 & 80 & 0 & 0 \\
\hline F2 & 20 & 80 & 10 & 0 \\
\hline F3 & 20 & 80 & 0 & 10 \\
\hline F4 & 20 & 80 & 10 & 10 \\
\hline
\end{tabular}

The papers to be used before the coating process were conditioned for 48 hours in laboratory conditions. The obtained paper coating formulations were coated with a laboratory type K303 Multi-coater (RK Print Coat Instruments Ltd, United Kingdom) with using Mayer Rod 2, at room temperature onto amount of $0.1 \mathrm{~g} / \mathrm{m}^{2}$ to one side of $80 \mathrm{~g} / \mathrm{m}^{2}$ paper at a speed of $2 \mathrm{~m} / \mathrm{min}$ and dried overnight in room conditions. The average thickness of the coatings was set to $3 \mu \mathrm{m}$.

\section{Determination of printability}

Uncoated and coated papers were printed with IGT C1 test printing machine using equal amount of process magenta ink (DIN ISO 2846-1). Printing parameters; $300 \mathrm{~N}$ printing pressure and $0.2 \mathrm{~m} / \mathrm{s}$ printing speed. The ink film thickness of all printed samples was measured as $8 \mu \mathrm{m}$.

\section{Characterization}

Zinc borate and coated papers FTIR spectrum were recorded on Perkin Elmer Spectrum100 ATR-FTIR spectrophotometer. Surface characterization were determined with Leica optical microscope.

The wettability of hybrid coatings was determined using the contact angle with the sessile water droplet method. The characteristics of surfaces were determined with contact angle (TAPPI T 458). Distilled water was used as standard wetting fluid in a Pocket Goniometer Model PG-X, (FIBRO Systems AB, Sweden), which was measured as a function of time. The program is of version 3.4. Images of water droplets were then recorded by using a CCD video camera. Surface energies were calculated on the contact angle by ASTM D5946 standard test method. The flammability characteristics of 
coatings were determined by LOI and UL-94 VTM tests. The LOI values of the coatings were measured by using an FTT (Fire Testing Technology) type instrument.

The color measurements of the coatings and prints on different coated paper were made by CIE L*a*b* method using X-Rite eXact spectrophotometer according to ISO 12647-2:2013 standard (International Organization for Standardization, 2013). The measurement conditions of the spectrophotometer are determined as polarization filter with $0^{\circ} / 45^{\circ}$ geometry with 2 observer angle with D50 light source in the range of 400-700 $\mathrm{nm}$. The difference between the colors of the different prints was calculated according to formula 1 according to the CIE $\triangle E 2000$ ISO 13655 standard.

$\Delta E_{00}=\sqrt{\left(\frac{\Delta L^{\prime}}{k_{L} S_{L}}\right)^{2}+\left(\frac{\Delta C^{\prime}}{k_{C} S_{C}}\right)^{2}+\left(\frac{\Delta H^{\prime}}{k_{H} S_{H}}\right)^{2}+R_{T} \frac{\Delta C^{\prime}}{k_{C} S_{C}} \frac{\Delta H^{\prime}}{k_{H} S_{H}}}$

The gloss measurements of coated papers were carried out with BYK Gardner $\mathrm{GmbH}$ micro gloss $75^{\circ}$ geometry in accordance with ISO 8254-1:2009, and the gloss measurements of prints with BYK Gardner GmbH micro Trigloss $60^{\circ}$ geometry in accordance with ISO 2813:2014.

\section{Results}

In this study, in order to produce flame retardant paper, coatings containing different reinforcements were made and their effects were investigated. For this purpose, zinc borate was synthesized to be used as a flame retardant additive. When the FTIR spectrum is examined, the bands at 3205-3456 $\mathrm{cm}^{-1}$ show O-H vibrations. O-H stress vibrations with hydrogen bond are observed at $2509 \mathrm{~cm}^{-1}$. The bands between 1292-1462 $\mathrm{cm}^{-1}$ and 857 $\mathrm{cm}^{-1}$ show asymmetric vibrations of the three-faced $\left(\mathrm{BO}_{3}\right)$ borate groups. In-plane bending vibration bands of B-O-H groups were exposed at $1254 \mathrm{~cm}^{-1}$. The peaks at $1062-1192 \mathrm{~cm}^{-1}$ and $792-858 \mathrm{~cm}^{-1}$ indicate asymmetric and symmetrical stress vibrations of the four-faced $\left(\mathrm{BO}_{4}\right)$ borate groups. The peak three-sided $\left(\mathrm{BO}_{3}\right)$ borate groups at $751 \mathrm{~cm}^{-1}$ show off-plane bending vibrations. When FTIR results are evaluated, it is seen that zinc borate is successfully synthesized. The results are consistent with the literature (Tugrul et al, 2015). SEM images of zinc borate are shown in Figure 2. The particle sizes of the zinc borate range from $350 \mathrm{~nm}$ to $1 \mu \mathrm{m}$.

The formulations in Table 1 were successfully prepared using the synthesized zinc borate and melamine, and coatings were applied to the paper surface. The chemical structures of the obtained nanocomposite coatings are explained by FTIR. When nanocomposite coatings spectrums are examined $\mathrm{OH}$ vibration of cellulose of paper $3294 \mathrm{~cm}^{-1}$, about $2900 \mathrm{~cm}^{-1}$ symmetric aliphatic C-H stretch vibration of methylene, and aromatic $\mathrm{C}=\mathrm{C}$ stretching vibrations at $1387 \mathrm{~cm}^{-1}$, these peaks clearly explain the cellulosic paper chemical structures (Danial et al, 2015). F1 showed that the $\mathrm{O}-\mathrm{H}$ vibration is becomes more prominent because of PVA molecules. It has emerged a peak $1268 \mathrm{~cm}^{-1}$ because of C-O of alcohol (Kaczmarek \& Podgorski, 2007). When F4 and F2 were examined, although the peaks of zinc borate appeared, they did not make a big distinction because they were too small in

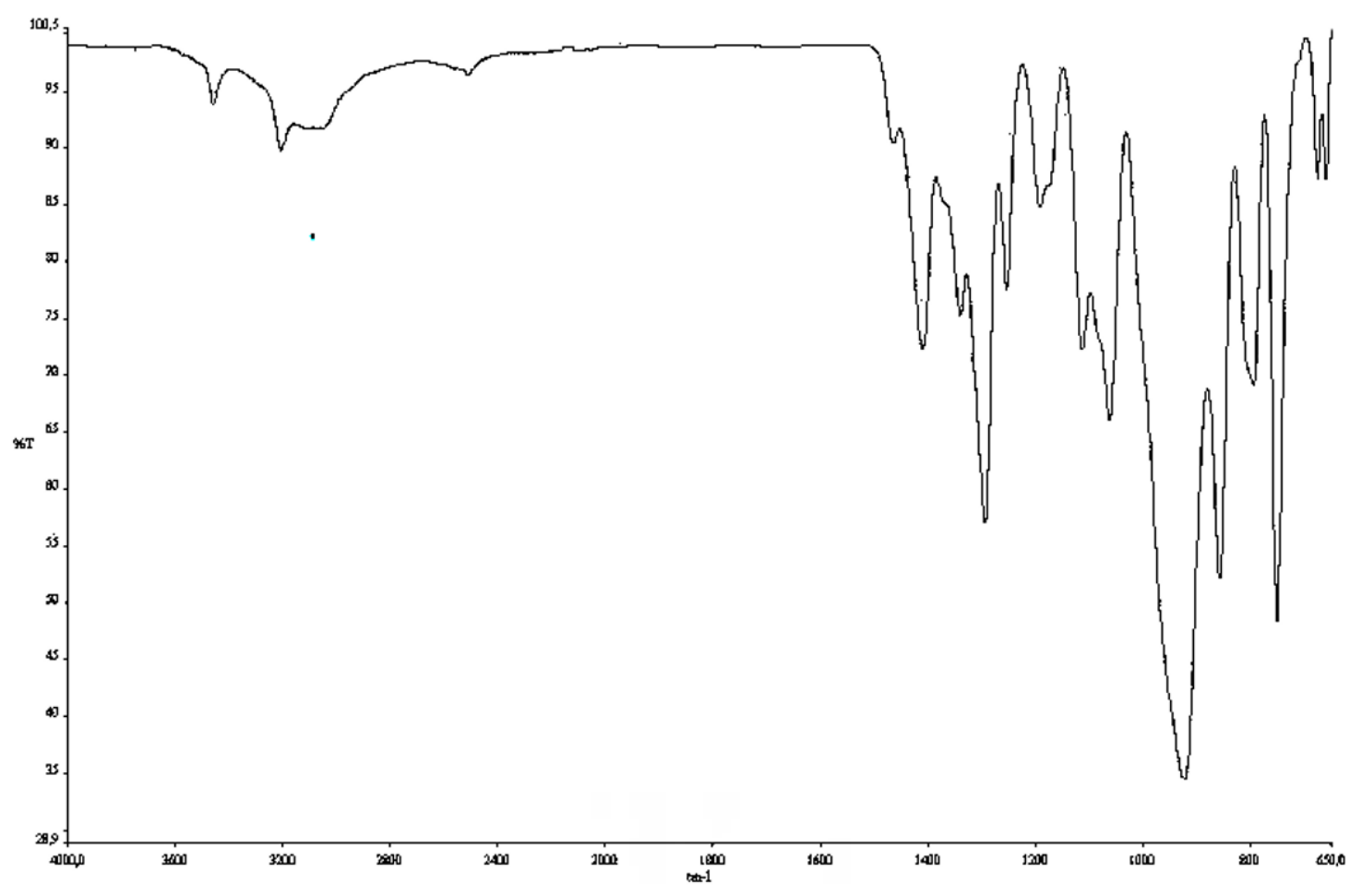

» Figure 1: ATR-FTIR spectra of zinc borate 
quantity besides PVA peaks. F3 exhibited that melamine added PVA coated paper. It is as a little vibration peak appeared $\mathrm{NH}_{2}$ peaks at $3468 \mathrm{~cm}^{-1}$, characteristic $1427 \mathrm{~cm}^{-1}$ C-N stretching of cyclo melamine, $1548.62 \mathrm{~cm}^{-1}$ sidechain asymmetry $\mathrm{C}-\mathrm{N}$ stretching and $\mathrm{C}-\mathrm{N}$ ring stretching of melamine was seen at spectrum (Ozcan et al, 2019).

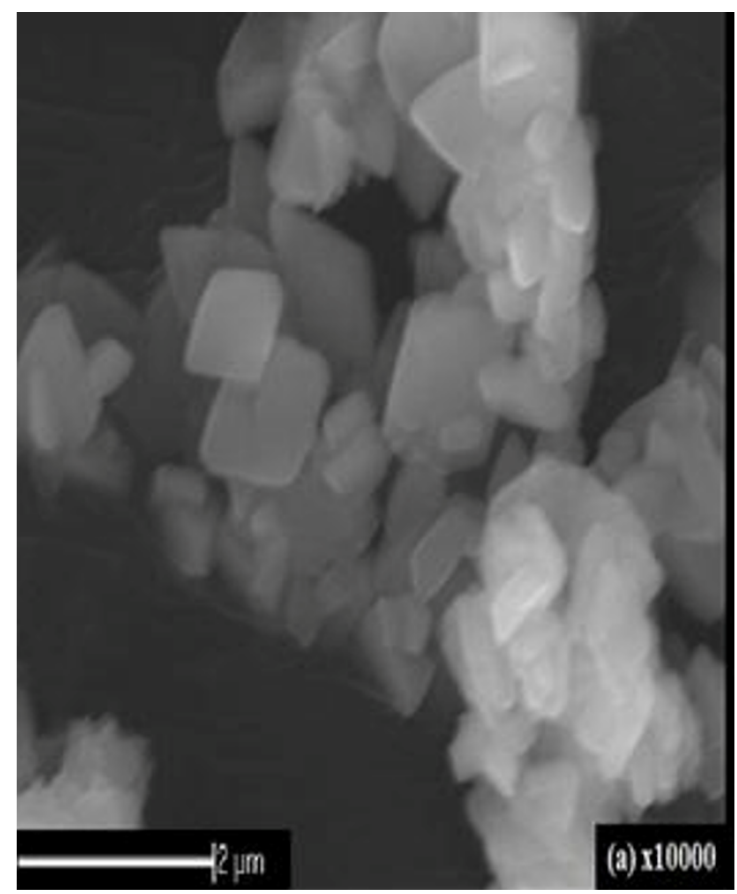

» Figure 2: SEM images of zinc borate
The properties of the obtained nanocomposite coatings such as color and gloss are determined and given in Table 2.

\section{Table 2}

Color and gloss values of nanocomposite coatings

\begin{tabular}{c|c|c|c|c|c}
\hline $\begin{array}{c}\text { Formulation } \\
\text { Number }\end{array}$ & $\mathbf{L}^{*}$ & $\mathbf{a}^{*}$ & $\mathbf{b}^{*}$ & $\mathbf{\Delta E}_{\mathbf{0 0}}$ & Gloss \\
\hline F0 & 95.46 & 2.91 & -10.21 & Standard & 5.2 \\
\hline F1 & 95.75 & 3.12 & -12.32 & 1.37 & 27.9 \\
\hline F2 & 96.78 & 2.73 & -11.86 & 1.48 & 26.2 \\
\hline F3 & 96.39 & 2.69 & -11.79 & 1.33 & 26.7 \\
\hline F4 & 95.98 & 2.71 & -11.81 & 1.28 & 25.8 \\
\hline
\end{tabular}

Untreated base paper was used as reference. When the color differences were examined, it was determined that the F1, F2, F3, F4 coatings shifted the color slightly to blue ( $b$ value) compared to the base paper. This is an expected result (Herrera et al, 2015). The color change $(\Delta E)$ is range about 1.28-1.48, and this value cannot be detected by the human eye. It is also within the acceptable reference range according to ISO 126472:2013 (International Organization for Standardization, 2013). When the gloss values were examined, it was

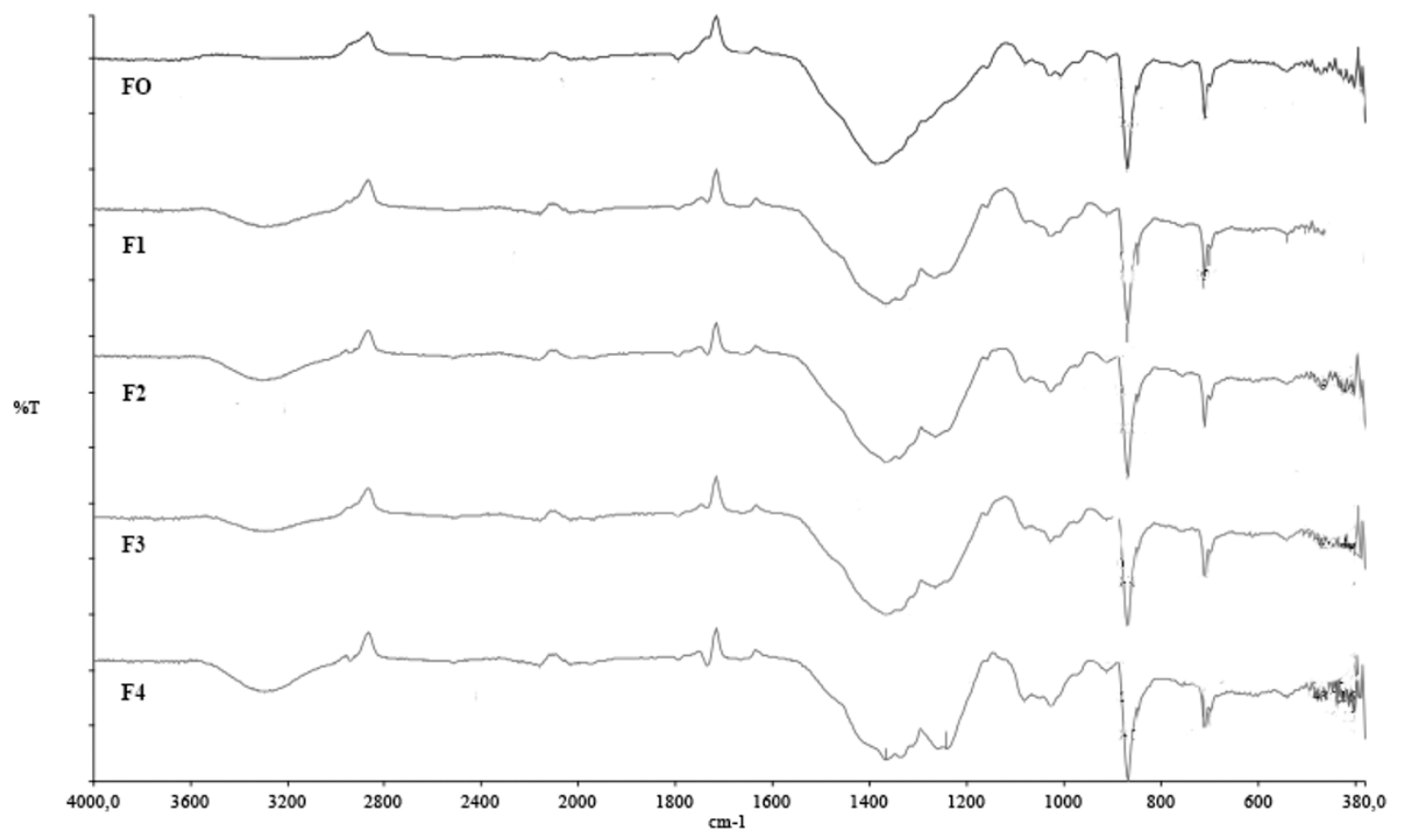

» Figure 3: ATR-FTIR spectra of FO (paper), F1(PVA-paper), F2 (PVA-paper-zinc borate), F3 (PVA-paper-melamine), F4 (PVA-paper-zinc borate-melamine) 
determined that all nanocomposite coatings were at least 5 times glossier than the base paper. This is due to the fact that the roughness on the paper surface is covered by the coating and the diffuse reflection is prevented. Thus, the papers became glossier. The results are similar to the literature (Chinga \& Helle, 2003).

Surface energy plays an important role in the interaction of paper with liquids. The contact angles and surface energies of the nanocomposite coatings are given in Table 3.

Table 3

Contact angle and surface energies of nanocomposite coatings

\begin{tabular}{c|c|c}
\hline $\begin{array}{c}\text { Formulation } \\
\text { Number }\end{array}$ & $\begin{array}{c}\text { Surface Energy } \\
\left(\mathbf{m} \mathbf{J} / \mathbf{m}^{\mathbf{2}}\right)\end{array}$ & $\begin{array}{c}\text { Contact Angle } \\
\left(\mathbf{(}^{\circ}\right)\end{array}$ \\
\hline F0 & 34.7 & 83.9 \\
\hline F1 & 46.2 & 52.1 \\
\hline F2 & 58.7 & 17.5 \\
\hline F3 & 50.6 & 40.0 \\
\hline F4 & 60.5 & 12.7 \\
\hline
\end{tabular}

When the contact angles of the coatings are examined, it is seen that the zinc borate decreases the contact angle and increases the wettability. In fact, it was determined that F2 had a super hydrophilic property. It has been determined that it decreases the contact angle in melamine, but this decrease is lower than zinc borate. Melamine reduces the contact angle due to its $\mathrm{H}$ bonds. It has been determined that it has very low contact angle in the $\mathrm{F} 4$ coating, which uses both zinc borate and melamine, that is, F4 has the properties of both. As expected, the surface energy increases as the contact angle increases.

The flame retardancy properties of nanocomposite paper coatings were examined with LOI measurements. LOI is widely used technique to determine the flame retardancy of coatings. LOI values of the nanocomposite paper coatings are given in figure 4 . As can be seen from Figure 4, all coatings increased the LOI. In F2, F3 and F4 LOI values was increased with addition of nano zinc borate and melamine. The greatest increase was seen in F4, where both substances were used together. The increase in the flame retardancy of nanocomposite paper coatings can be attributed to the synergistic effect of borate and melamine. When flame retardancy is examined; It was determined that the LOI value of the paper increased by $58 \%$ when compared with F4.

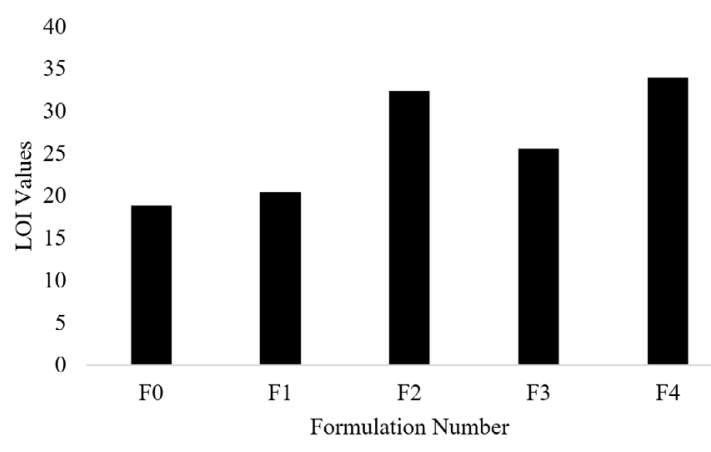

» Figure 4: LOI values of FO, F1, F2, F3 and F4 nanocomposite paper coatings

Offset test prints were made with IGT C1 on the surface of all coated paper. CIE L*a*b* color, gloss, color differences of the obtained prints are given in Table 4. When Table 4 is examined; As with coatings, it is seen that FO, F1 and F3 direct the color towards blue in their prints. F2 directed the color to a little yellow. The color difference in the coatings $\left(\Delta \mathrm{E}_{00}\right)$ is reduced. This shows that the ink tolerates the color difference of the magenta tone. The color differences of the prints on all coatings are within the tolerance limits according to ISO 12647-2 (International Organization for Standardization, 2013). When the gloss values were examined, parallel results were obtained. The reason for the decrease in gloss of all prints is that the pigment in the ink distributes the light slightly. Thus, surface roughness and diffuse reflection increased, gloss decreased.

\section{Table 4}

Printability parameters of coatings

\begin{tabular}{c|c|c|c|c|c}
\hline $\begin{array}{c}\text { Formulation } \\
\text { Number }\end{array}$ & $\mathbf{L}^{*}$ & $\mathbf{a}^{*}$ & $\mathbf{b}^{*}$ & $\mathbf{\Delta E}_{\mathbf{0 0}}$ & $\mathbf{G l o s s}$ \\
\hline F0 & 47.24 & 73.94 & -3.55 & Standard & 1.8 \\
\hline F1 & 48.42 & 74.21 & -5.61 & 1.32 & 17.1 \\
\hline F2 & 48.57 & 74.74 & -4.82 & 1.37 & 15.2 \\
\hline F3 & 48.19 & 73.49 & -5.29 & 0.64 & 15.1 \\
\hline F4 & 47.94 & 73.61 & -5.21 & 0.86 & 14.9 \\
\hline
\end{tabular}

\section{Conclusions}

In this study, PVA based flame retardant (zinc borate and/or melamine) containing paper coating nanocomposite formulations were successfully prepared and applied on paper. It was determined that the colors of the coated papers containing flame retardant shifted to blue. However, deviations in colors are small enough to be ignored. In addition, all coatings significantly increased the gloss of the base paper. Depending on 
the nature of the additives, the printability of the paper has been increased due to the wettability of paper. When examined thermally; the highest thermal stability was observed in paper coatings containing zinc borate and zinc borate/melamine. Similarly, flame retardancy properties of coatings were compared with LOI. It was determined that all of the coatings ignited later. In the light of these results, all coatings obtained will take longer to ignite the paper and thus have more time to recover valuable documents. Prints were made on the coated papers and it was determined that the coating types did not change the color of printings much. As a result, hybrid coatings made within the scope of this study have improved the printability properties as well as adding flame retardancy properties to the paper.

\section{References}

Acarali, N. B., Ozturk, E., Bardakci, M., Piskin, M. B. \& Tugrul, N. (2015) Zinc borate production with boron mineral source: effect of process parameters on yield and hydrophobicity. Gospodarka Surowcami Mineralnymi. 31 (4), 95-110. Available from: doi: 10.1515/ gospo-2015-0040

Auras, R. A., Lim, L. T., Selke, S. E. \& Tsuji, H. (Eds.) (2011) Poly (lactic acid): synthesis, structures, properties, processing, and applications. 10. Hoboken, New Jersey, John Wiley \& Sons. Available from: doi: 10.1002/9780470649848

Avella, M., Buzarovska, A., Errico, M. E., Gentile, G. \& Grozdanov, A. (2009) Eco-challenges of bio-based polymer composites. Materials. 2 (3), 911-925. Available from: doi: 10.3390/ma2030911

Avérous, L. (2008) Polylactic acid: synthesis, properties and applications. In: Belgacem, M.N., Gandini, A. (eds.) Monomers, polymers and composites from renewable resources. Amsterdam, Netherlands, Elsevier, pp. 433-450. Available from: doi: 10.1016/B978-0-08045316-3.00021-1

Chandra, R. \& Rustgi, R. (1998) Biodegradable polymers. Progress in Polymer Science. 23 (7), 1273-1335. Available from: doi: 10.1016/S0079-6700(97)00039-7

Chang, Y. L., Wang, Y. Z., Ban, D. M., Yang, B. \& Zhao, G. M. (2004) A novel phosphorus-containing polymer as a highly effective flame retardant. Macromolecular Materials and Engineering. 289 (8), 703-707. Available from: doi: 10.1002/mame.200400064

Chinga, G. \& Helle, T. (2003) Relationships between the coating surface structural variation and print quality. Journal of Pulp and Paper Science. 29 (6), 179-184.

Danial, W. H., Majid, Z. A., Muhid, M. N. M., Triwahyono, S., Bakar, M. B. \& Ramli, Z. (2015) The reuse of wastepaper for the extraction of cellulose nanocrystals. Carbohydrate polymers. 118, 165-169. Available from: doi: 10.1016/j.carbpol.2014.10.072

Duncan, T. V. (2011) Applications of nanotechnology in food packaging and food safety: barrier materials, antimicrobials and sensors. Journal of Colloid and Interface Science. 363 (1), 1-24. Available from: doi: 10.1016/j.jcis.2011.07.017

Garba, B. (1999) Effect of zinc borate as flame retardant formulation on some tropical woods. Polymer Degra- dation and Stability. 64 (3), 517-522. Available from: doi: 10.1016/S0141-3910(98)00136-0

Herrera, R., Muszyńska, M., Krystofiak, T. \& Labidi, J. (2015) Comparative evaluation of different thermally modified wood samples finishing with UV-curable and waterborne coatings. Applied Surface Science. 357, 1444-1453. Available from: doi: 10.1016/j. apsusc.2015.09.259

Hirschler, M. M. (1984) Reduction of smoke formation from and flammability of thermoplastic polymers by metal oxides. Polymer. 25 (3), 405-411. Available from: doi: 10.1016/0032-3861(84)90296-9

Horacek, H., \& Grabner, R. (1996) Advantages of flame retardants based on nitrogen compounds. Polymer Degradation and Stability. 54 (2-3), 205-215. Available from: doi: 10.1016/S0141-3910(96)00045-6

International Organization for Standardization. (2013) ISO 12647-2:2013. Graphic technology - Process control for the production of half-tone colour separations, proof and production prints - Part 2: Offset lithographic processes. Geneva, International Organization for Standardization.

Kaczmarek, H. \& Podgórski, A. (2007) The effect of UV-irradiation on poly (vinyl alcohol) composites with montmorillonite. Journal of Photochemistry and Photobiology A: Chemistry. 191 (2-3), 209-215. Available from: doi: 10.1016/j.jphotochem.2007.04.025

Kuorwel, K. K., Cran, M. J., Sonneveld, K., Miltz, J. \& Bigger, S. W. (2011) Antimicrobial activity of biodegradable polysaccharide and protein-based films containing active agents, Journal of Food Science. 76 (3), R90-R102. Available from: doi: 10.1111/j.17503841.2011.02102.x

Lu, S. Y. \& Hamerton, I. (2002) Recent developments in the chemistry of halogen-free flame retardant polymers. Progress in Polymer Science. 27 (8), 1661-1712. Available from: doi: 10.1016/S0079-6700(02)00018-7

Mohanty, A. K., Misra, M. \& Drzal, L. T. (Eds.) (2005) Natural fibers, biopolymers, and biocomposites. Boca Raton, Florida, CRC press. Available from: doi: 10.1201/9780203508206

Ozcan, A., Kandirmaz, E. A., Hayta, P. \& Mutlu, B. (2019) Examination of the effect of melamine as a filler in paper coatings on print quality. Cellulose Chemistry and Technology. 53 (3-4), 307-313. Available from: doi: 10.35812/CelluloseChemTechnol.2019.53.30

Pilla, S. (Ed.) (2011) Handbook of bioplastics and biocomposites engineering applications. 81, Hoboken, New Jersey, John Wiley \& Sons. Available from: doi: 10.1002/9781118203699

Ren, H., Sun, J., Wu, B. \& Zhou, Q. (2007) Synthesis and properties of a phosphorus-containing flame retardant epoxy resin based on bis-phenoxy (3-hydroxy) phenyl phosphine oxide. Polymer Degradation and Stability. 92 (6), 956-961. Available from: doi: 10.1016/j.polymdegradstab.2007.03.006

Siracusa, V., Rocculi, P., Romani, S. \& Dalla Rosa, M. (2008) Biodegradable polymers for food packaging: a review. Trends in Food Science \& Technology. 19 (12), 634-643. Available from: doi: 10.1016/j. tifs. 2008.07.003

Tugrul, N., Bardakci, M. \& Ozturk, E. (2015) Synthesis of hydrophobic nanostructured zinc borate from zinc carbonate, and characterization of the product. Research on Chemical Intermediates. 41 (7), 4395-4403. Available from: doi: 10.1007/s11164-014-1538-4 


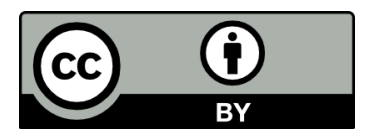

(C) 2020 Authors. Published by the University of Novi Sad, Faculty of Technical Sciences, Department of Graphic Engineering and Design. This article is an open access article distributed under the terms and conditions of the Creative Commons Attribution license 3.0 Serbia (http://creativecommons.org/licenses/by/3.0/rs/). 